
out-dez 2004

\title{
Desempenho de linhagens de melão rendilhado em casa de vegetação
}

\author{
Adriana Antonieta do N. Rizzo; Leila T. Braz \\ UNESP-FCAV, Depto. Produção Vegetal, Via de Acesso Prof. Paulo Donato Castellane, s/n, 14884-900 Jaboticabal-SP; E- \\ mail:drarizzo@fcav.unesp.br
}

\section{RESUMO}

Avaliaram-se 20 linhagens de melão rendilhado, obtidas em programa de melhoramento genético do meloeiro da UNESP, com relação às características associadas à produção e qualidade dos frutos. $\mathrm{O}$ experimento foi conduzido em casa de vegetação da UNESP em Jaboticabal, de junho de 2001 a dezembro de 2002. Utilizou-se o delineamento de blocos ao acaso com 20 tratamentos (linhagens), em quatro repetições. Cada parcela foi composta por oito plantas no espaçamento $0,5 \times 1,0 \mathrm{~m}$. Foram avaliados a produtividade $\left(\mathrm{g} / \mathrm{m}^{2}\right)$, peso médio, diâmetro transversal e longitudinal do lóculo e do fruto, índice de formato do fruto, espessura e coloração do mesocarpo e do epicarpo e teor de sólidos solúveis ( $\left.{ }^{\circ} \mathrm{Brix}\right)$ dos frutos. As linhagens JAB-24-3, JAB-24-4, JAB-24-5, JAB-24-7, JAB-24-8, JAB24-9, JAB-24-11, JAB-24-12, JAB-24-13, JAB-24-14, JAB-24-15, JAB-24-18 e JAB-24-20 se destacaram das demais na maioria das características avaliadas, demonstrando bom potencial para obtenção de híbridos comerciais.

Palavras-chave: Cucumis melo var. reticulatus Naud., cultivo protegido, qualidade de frutos.

\begin{abstract}
Muskmelon lines evaluation at greenhouse

Twenty lines of muskmelon were evaluated in a greenhouse in relation to characteristics associated with yield and fruit quality. The assay was carried out in Jaboticabal, São Paulo State, Brazil from June 2001 to December 2002. The 20 lines were evaluated in a complete randomized block design with four replications. Each plot consisted of 8 plants spaced $0.5 \times 1.0$ m apart. We evaluated the total fruit yield; average fruit weight; average longitudinal and transversal fruit diameter; index fruits shape, average thickness and flesh and skin color and \% total soluble solids. The inbred lines JAB-24-3, JAB-24-4, JAB-24-5, JAB-24-7, JAB-24-8, JAB-24-9, JAB-24-11, JAB-24-12, JAB-24-13, JAB-24-14, JAB-24-15, JAB24-18 and JAB-24-20 showed potential for using as parentals for the commercial hybrids production.
\end{abstract}

Keywords: Cucumis melo var. reticulatus Naud., greenhouse, fruit quality.

\section{(Recebido para publicação em 2 de setembro de 2003 e aceito em 23 de julho de 2004)}

A tualmente, $70 \%$ dos melões pro duzidos no Brasil são do tipo amarelo, pertencente ao grupo botânico Inodorus e os $30 \%$ restantes da produção são de melões considerados nobres (Silva et al., 2000). Dentre os melões nobres estão os rendilhados, pertencentes ao grupo botânico Cantalupensis (Robinson e Decker-Walters, 1997). Estes melões caracterizam-se por apresentar a superfície do fruto rendilhada, formato redondo a ovalado, aroma característico, polpa bastante doce (Brix ao redor de $10^{\circ}$ ) e coloração que varia de verde-clara a salmão (Siviero, 1993).

Nas últimas duas décadas, verificouse um aumento na produção de melões rendilhados nas áreas tradicionalmente produtoras de melões no Nordeste e em cultivo protegido nas regiões Sul e $\mathrm{Su}$ deste do país. Este aumento na produção se deve à possibilidade de maior lucratividade que pode ser alcançada em pequenas áreas em algumas épocas do ano, quando a cultura do melão rendilhado é utilizada em rotação às culturas costumeiramente cultivadas em ambiente protegido e, principalmente, pela possibilidade de exploração do mercado externo europeu, que tem mostrado boa aceitação dos melões oriundos do Brasil. Esta possibilidade é ainda ampliada, pois, o período de entressafra europeu é coincidente com a melhor época de produção brasileira, que vai de setembro a abril (Silva et al., 2000).

O consumo de melão rendilhado está relacionado ao teor de sólidos solúveis, responsável pelo sabor e ao seu aspecto visual, que o diferencia dos outros tipos de melões existentes no mercado. Sua qualidade nutricional também tem contribuído favoravelmente para o seu consumo, pois são considerados pouco calóricos e boa fonte de sódio, potássio, vitaminas A e C (Lester, 1997).

A qualidade em frutos de melão envolve atributos relacionados à precocidade e concentração da produção, aparência (formato, coloração da casca e polpa e presença ou não de rendilhamento), qualidade de polpa e resistência ao armazenamento. A qualidade de polpa é influenciada pelo teor de açúcares, aroma, textura, firmeza e coloração. O teor de açúcares é influenciado principalmente pelo conteúdo de sacarose. Comercialmente, frutos com teores de sólidos solúveis entre 12-15\% são considerados de excelente qualidade; teores próximos de $9 \%$ são considerados aceitáveis e, abaixo deste valor, não são comerciáveis (Odet, 1992; McCreight et al., 1993; Gorgatti Neto et al., 1994; Silva et al., 2000).

Para Odet (1992), além dos aspectos externos e internos, a qualidade em frutos de melão é definida também pelo valor nutricional e condições sanitárias destes.

Outro aspecto importante comercialmente é o índice do formato do fruto em melão, que é obtido pela razão entre o diâmetro transversal e longitudinal do fruto. Este atributo está relacionado ao acondicionamento e transporte dos frutos, sendo um parâmetro usado para a classificação destes e adequação ao tipo de embalagem e mercado consumidor a que se destina (Pádua, 2001). Os valores de índices considerados ideais estão 
relacionados às características das cultivares e seus respectivos grupos botânicos, variando segundo formato padrão dos frutos.

Lopes (1982) classifica os frutos de acordo com seu índice de formato (IF) como: esféricos $(\mathrm{IF}=1)$; oblongos (entre 1,1 e 1,7 ) e cilíndricos (maior que 1,7). Pádua (2001), avaliando três cultivares ('Bônus n' 2', 'Don Carlos' e 'HyMark') em solo e substrato, no inverno e verão, observou que a cv. Bônus $n^{\circ} 2$ apresentou formato esférico ( $\mathrm{IF}=1,07)$. Já as cultivares Hy-Mark e Don Carlos apresentaram frutos alongados $(\mathrm{IF}=1,23$ e 1,21, respectivamente).

$\mathrm{O}$ fruto ideal deve ter polpa espessa e, conseqüentemente, uma cavidade interna pequena, pois frutos deste tipo resistem melhor ao transporte e têm maior durabilidade pós-colheita (Costa e Pinto, 1977).

A escolha dos frutos de melão pelos consumidores ocorre primeiramente pelo teor de açúcar deste, sendo considerado o principal aspecto qualitativo, depois pelo aroma e coloração da polpa e por último pela consistência ou firmeza que este apresenta (Lester e Turley, 1990).

O consumo de melões amarelos no Brasil ainda é predominante mas à medida em que os consumidores têm contato com os melões nobres, este panorama pode ser alterado. Duarte e Andrade Júnior (2003) indicam que há tendência atual no mercado para o aumento da demanda por melões nobres, aromáticos, de polpa salmão e com alto teor de açúcar.

Alguns estudos têm sido realizados considerando-se estes fatores de qualidade de frutos, que contribuem para a aproximação entre mercado consumidor e programas de melhoramento.

O teor total de sólidos solúveis pode ser influenciado por fatores genéticos (capacidade de acúmulo ou conversão de açúcares), ambientais (baixas temperaturas noturnas favorecem o acúmulo), fisiológicos (taxa fotossintética, área foliar disponível, entre outros) e manejo adequado do cultivo (controle de irrigação e nutrição das plantas) (Welles e Buitelaar, 1988).

Rizzo e Braz (2001) avaliaram em cinco cultivares de melão rendilhado (Sunrise, Aragon, Halest Best Jumbo,
Nero e Bônus $n^{\circ}$ 2) características associadas a produção e qualidade de frutos em casa de vegetação. Foram avaliados nestes híbridos o peso médio dos frutos comercializáveis; diâmetro e comprimento médio de frutos; espessura média e coloração do mesocarpo e epicarpo; teor de sólidos solúveis totais ( $\left.{ }^{\circ} \mathrm{Brix}\right), \mathrm{pH}$ e acidez total. O híbrido Bônus $\mathrm{n}^{\circ} 2$ destacou-se com relação à produção $\left(13,15 \mathrm{~kg} / \mathrm{m}^{2}\right.$, com três frutos por planta), peso médio dos frutos $(693,2 \mathrm{~g})$, espessura do mesocarpo $(2,8 \mathrm{~cm})$, diâmetros médios transversal e longitudinal do fruto $(10,20$ e $10,48 \mathrm{~cm}$, respectivamente) e teor de sólidos solúveis totais $\left(13,1^{\circ}\right.$ Brix $)$, que variou entre 8,3 a $13,1^{\circ}$ Brix entre os híbridos testados.

Gusmão (2001) avaliou o comportamento de oito híbridos de melão rendilhado (Mission, Bônus $\mathrm{n}^{\circ}$ 2, Don Carlos, Louis, Pacstar, PPAA, Don Domingos e Nero) em diversas condições de cultivo (diferentes épocas, densidade de plantio, presença ou ausência de coberturas de canteiros, campo aberto, túnel baixo e casa de vegetação) com relação ao número de frutos, produção total $/ \mathrm{m}^{2}$, diâmetro médio de frutos, índice de rendilhamento e teor de sólidos solúveis. Bônus no 2 e Nero apresentaram maior produção total e peso médio de frutos. Os híbridos Don Carlos, Pacstar e PPAA apresentaram valores superiores a $9 \%$ para sólidos solúveis totais nas diferentes condições de cultivo. $\mathrm{O}$ índice de rendilhamento variou entre os híbridos de acordo com as condições de plantio.

Welles e Buitelaar (1988) avaliando o comportamento de quatro cultivares de melão (Haon, Gália, Chaca e Aroma), em cinco experimentos realizados durante a primavera, verão e outono, em casas de vegetação aquecidas, verificaram que a quantidade de frutos por planta, área foliar, temperatura noturna e o estádio de maturação, influenciaram no conteúdo total de sólidos solúveis. Todas as características avaliadas demonstraram influenciar o conteúdo total de sólidos solúveis, exceto a quantidade de frutos por planta. Em todos os experimentos, o período de maturação do fruto, correspondente ao período entre o pegamento do fruto e a colheita, correlacionou-se positivamente com conteúdo total de sólidos solúveis. Os autores sugerem ainda que temperaturas noturnas baixas durante o período do crescimento dos frutos, maior área foliar, colheita de frutos maduros e seleção de cultivares com amadurecimento tardio podem contribuir para obtenção de frutos com elevado conteúdo total de sólidos solúveis.

Até o momento não se dispõe de cultivares de melão rendilhado nacionais, que estejam adaptadas às condições brasileiras e que atendam às necessidades para plantios comerciais, não existindo ainda produção de sementes híbridas, sendo as sementes híbridas utilizadas originárias principalmente do Japão e EUA. Portanto, faz-se necessário o estudo de genótipos que possam ser utilizados como genitores de futuros híbridos que contribuirão para o desenvolvimento e adaptação desta cultura às nossas condições.

Com este intuito, neste trabalho, objetivou-se avaliar 20 linhagens de melão rendilhado, cultivados em casa de vegetação, com relação à produção e qualidade dos frutos, visando sua utilização futura como genitores.

\section{MATERIAL E MÉTODOS}

O experimento foi conduzido em casa de vegetação da UNESP, Câmpus de Jaboticabal (SP).

A casa de vegetação utilizada é do tipo arco, com $50 \mathrm{~m}$ x $6 \mathrm{~m}$, pé direito de 3,5 m, e tela de proteção lateral. A irrigação foi realizada por gotejamento e as temperaturas máxima e mínima durante o período de condução do ensaio variaram entre 18,1 e 37,8 (máxima) e 5,4 e 22,4 (mínima). Utilizou-se o delineamento em blocos ao acaso com quatro repetições e 20 tratamentos compostos pelas linhagens identificadas da seguinte forma: JAB-24-1, JAB-24-2, JAB-24-3, JAB-24-4, JAB-24-5, JAB24-6, JAB-24-7, JAB-24-8, JAB-24-9, JAB-24-10, JAB-24-11, JAB-24-12, JAB-24-13, JAB-24-14, JAB-24-15, JAB-24-16, JAB-24-17, JAB-24-18, JAB-24-19 e JAB-24-20.

Estas linhagens foram escolhidas a partir de um banco de germoplasma mantido pela FCAV da UNESP, que tem por objetivo a obtenção de híbridos de 
Tabela 1. Valores médios de sete características de frutos de 20 linhagens de melão rendilhado. Jaboticabal (SP), FCAV-UNESP, 2002.

\begin{tabular}{|c|c|c|c|c|c|c|c|}
\hline Linhagens & $P(g / m 2)$ & PF (g) & DTF (cm) & DLF (cm) & IF & DTL (cm) & DLL (cm) \\
\hline JAB-24-1 & 2390,3 bcd $^{1}$ & $597,6 \mathrm{bcd}$ & $10,4 a$ & $11,0 \mathrm{bcd}$ & $1,07 a b c$ & $5,4 a b$ & 7,0 abcd \\
\hline JAB-24-2 & $2236,5 \mathrm{~cd}$ & $559,1 \mathrm{~cd}$ & 11,0 a & $11,9 a b c$ & $1,12 a b$ & $5,9 a b$ & 7,9 a \\
\hline JAB-24-3 & $3259,4 \mathrm{abcd}$ & $814,8 \mathrm{abcd}$ & $11,2 a$ & $11,6 \mathrm{abcd}$ & $1,02 a b c$ & $5,9 a b$ & $7,3 a b c$ \\
\hline JAB-24-4 & $2908,8 \mathrm{abcd}$ & $727,2 \mathrm{abcd}$ & $11,2 a$ & 10,9 bcde & $0,97 \mathrm{abc}$ & $5,7 a b$ & 6,6 abcde \\
\hline JAB-24-5 & $2556,2 \mathrm{abcd}$ & $639,0 \mathrm{abcd}$ & $10,7 a$ & $10,5 \mathrm{cde}$ & $1,02 a b c$ & $5,8 \mathrm{ab}$ & 6,7 abcde \\
\hline JAB-24-6 & $2408,7 \mathrm{bcd}$ & $602,2 \mathrm{bcd}$ & $10,5 a$ & $9,8 \mathrm{de}$ & $0,95 \mathrm{bc}$ & $5,2 a b$ & $6,4 \mathrm{cde}$ \\
\hline JAB-24-7 & $1929,6 \mathrm{~d}$ & $482,4 d$ & $5,4 \quad b$ & $9,2 \mathrm{e}$ & $0,92 \mathrm{c}$ & $5,0 \quad b$ & $5,5 \mathrm{e}$ \\
\hline JAB-24-8 & $2988,3 \mathrm{abcd}$ & $747,1 \mathrm{abcd}$ & $11,2 a$ & $11,1 \mathrm{bcd}$ & $1,00 a b c$ & $5,1 \quad b$ & $6,9 \mathrm{abcd}$ \\
\hline JAB-24-9 & 3878,3 a & 969,6 a & 12,5 a & $12,5 a b$ & $1,00 a b c$ & 6,6 a & $7,9 a b$ \\
\hline JAB-24-10 & $2734,5 \mathrm{abcd}$ & $673,6 \mathrm{abcd}$ & $10,2 a$ & 10,6 bcde & $1,07 a b c$ & $5,6 a b$ & $6,9 \mathrm{abcd}$ \\
\hline JAB-24-11 & $3556,2 \mathrm{abc}$ & $889,0 \mathrm{abc}$ & 9,8 a & 10,8 bcde & $1,15 \mathrm{a}$ & $5,7 a b$ & $6,2 \mathrm{cde}$ \\
\hline JAB-24-12 & $2675,0 \mathrm{abcd}$ & $668,7 \mathrm{abcd}$ & $10,8 a$ & 10,4 cde & $0,97 a b c$ & $5,4 a b$ & 6,5 bcde \\
\hline JAB-24-13 & $2664,3 \mathrm{abcd}$ & $666,1 \mathrm{abcd}$ & $10,7 a$ & 10,3 cde & $1,00 a b c$ & $5,8 \mathrm{ab}$ & $6,1 \mathrm{cde}$ \\
\hline JAB-24-14 & $3262,8 \mathrm{abcd}$ & $815,7 \mathrm{abcd}$ & $11,3 a$ & $11,4 \mathrm{abcd}$ & $1,12 a b$ & $5,8 \mathrm{ab}$ & $6,8 \mathrm{abcd}$ \\
\hline JAB-24-15 & 2634,8 abcd & $658,7 \mathrm{abcd}$ & $10,8 a$ & $11,1 \mathrm{bcd}$ & $1,00 \mathrm{abc}$ & $5,6 a b$ & 6,7 abcde \\
\hline JAB-24-16 & $2475,0 \mathrm{bcd}$ & $618,7 \mathrm{bcd}$ & $10,0 a$ & $11,1 \mathrm{bcd}$ & $1,12 a b$ & $5,4 a b$ & $6,8 \mathrm{abcd}$ \\
\hline JAB-24-17 & $1925,0 \mathrm{~d}$ & $481,2 d$ & $10,0 a$ & 9,9 de & $1,00 a b c$ & $5,7 \mathrm{ab}$ & $6,4 \mathrm{cde}$ \\
\hline JAB-24-18 & $2671,4 \mathrm{abcd}$ & $667,8 \mathrm{abcd}$ & $10,3 a$ & $9,8 \mathrm{de}$ & $0,97 \mathrm{abc}$ & $6,3 \mathrm{ab}$ & $6,1 \mathrm{cde}$ \\
\hline JAB-24-19 & $2214,8 d$ & $553,7 d$ & 9,8 a & $9,8 \mathrm{de}$ & $1,00 a b c$ & $5,1 \quad b$ & $5,8 \mathrm{de}$ \\
\hline JAB-24-20 & $3672,5 \mathrm{ab}$ & $918,1 \mathrm{ab}$ & 12,6 a & $13,1 \mathrm{a}$ & $1,05 \mathrm{abc}$ & $6,2 a b$ & 7,9 a \\
\hline C.V. (\%) & 18,54 & 18,57 & 12,4 & 6,47 & 7,09 & 9,61 & 7,75 \\
\hline DMS (Tukey) & 1340,3376 & 335,2477 & 3,4300 & 1,8476 & 0,1903 & 1,4311 & 1,3738 \\
\hline
\end{tabular}

Médias seguidas da mesma letra na mesma coluna não diferem entre si pelo teste de Tukey a 5\% de probabilidade; $\mathrm{P}=$ produtividade; $\mathrm{PF}=$ peso médio de frutos; $\mathrm{DTF}=$ diâmetro transversal de frutos; $\mathrm{DLF}=$ diâmetro longitudinal de frutos; $\mathrm{IF}=$ índice de formato de frutos; DTL=diâmetro transversal do lóculo; DLL=diâmetro longitudinal do lóculo

melão rendilhado adaptados as condições regionais. Estas 20 linhagens selecionadas possuem bom desempenho em teor de sólidos solúveis, espessura de polpa, produção total, peso médio de frutos, aparência apreciada pelos consumidores.

Cada parcela foi constituída por duas linhas de 4,0 metros de comprimento, com oito plantas. $\mathrm{O}$ espaçamento adotado foi de $1,0 \mathrm{~m}$ entre fileiras e $0,5 \mathrm{~m}$ entre plantas. A semeadura foi realizada em junho de 2002, utilizando-se de bandejas de poliestireno expandido com 128 células, preenchidas com substrato para hortaliças $\left(\mathrm{Plantmax}^{\mathrm{O}}\right)$. O transplantio para a casa de vegetação foi realizado quando as mudas apresentavam a primeira folha definitiva. As adubações de plantio e cobertura foram realizadas com base em análise de solo, segundo recomendações de Raij et al. (1996) para a cultura. O tutoramento das plantas foi feito com fitilhos plásticos presos a arames localizados rente ao solo e a 2,0 m de altura. Foi conduzida uma planta por cova, e realizou-se desbrotas (até o $8^{\circ}$ nó e após a fixação dos frutos) e amarrios das plantas sempre que necessário. Os demais tratos culturais foram realizados seguindo as indicações para a cultura. Foram deixados dois frutos por planta e a colheita foi iniciada no mês de novembro de 2002, a partir da maturação dos frutos.

Foram coletados dados de produção total de frutos $\left(\mathrm{g} / \mathrm{m}^{2}\right)$, peso médio dos frutos $(\mathrm{g})$; diâmetro médio transversal e longitudinal $(\mathrm{cm})$; índice de formato de frutos (obtido pela razão entre médias dos diâmetros longitudinal e transversal de frutos); diâmetro médio transversal e longitudinal do lóculo (cm), espessura média do mesocarpo e epicarpo (cm); coloração do mesocarpo e epicarpo, determinada de acordo com escala de notas $(1=$ verde, $2=$ amarelo e $3=$ laranja) (Rizzo, 2004); rendilhamento da casca, caracterizado por avaliação visual determinada de acordo com escala de notas ( $1=$ fraco, 2= médio e 3= intenso) (Rizzo, 2004) e teor de sólidos solúveis totais ( ${ }^{\circ} \mathrm{Brix}$ ), obtido em refratômetro manual. Com os dados médios de cada característica, realizou-se a análise de variância, aplicou- se o teste $\mathrm{F}$ e quando o valor de F calculado foi significativo, realizou-se comparações entre as médias pelo teste de Tukey ao nível de $5 \%$ de probabilidade.

\section{RESULTADOS E DISCUSSÃO}

Todas as características avaliadas apresentaram diferenças significativas entre as linhagens, à exceção da espessura média do epicarpo (Tabelas 1 e 2).

Os maiores valores de produtividade e peso médio de frutos foram obtidos pela linhagem JAB-24-9, que diferiu apenas das linhagens JAB-24-1, JAB-24-2, JAB-24-6, JAB-24-7, JAB24-16, JAB-24-19, e JAB-24-17 (Tabela 1$)$. A produtividade alcançada pela linhagem JAB-24-9, considerando-se que foram deixados dois frutos por planta, atingiu valores próximos aos encontrados por Rizzo e Braz (2001) e Gusmão (2001), indicando bom potencial produtivo.

Existe uma tendência do mercado consumidor de preferir frutos com peso próximo a $1 \mathrm{~kg}$. Dentre as linhagens avaliadas, JAB-24-9 apresentou valores 
próximos aos obtidos por Hartz (1997) e indicados por Siviero (1993) como ideais.

A linhagem JAB-24-7 apresentou os menores valores médios de diâmetro transversal e longitudinal de frutos, diferindo das demais linhagens. Para o diâmetro transversal de frutos obtiveram-se valores variando entre 9,8 e 12,6 cm. Nas linhagens JAB-24-1, JAB-2416, JAB-24-15, JAB-24-8, JAB-24-14, JAB-24-3, JAB-24-2, JAB-24-9 e JAB24-20, para diâmetro longitudinal de frutos, os valores variaram entre 9,2 e 13,1 $\mathrm{cm}$, próximos aos encontrados por Rizzo e Braz (2001).

As linhagens JAB-24-7, JAB-24-19 apresentaram os menores valores médios de diâmetro transversal do lóculo, não diferindo das demais linhagens (Tabela 1).

A linhagem JAB-24-7 também apresentou o menor valor médio de diâmetro longitudinal do lóculo, diferindo das linhagens JAB-24-1, JAB-24-2, JAB24-3, JAB-24-8 JAB-24-9, JAB-24-20, JAB-24-3, JAB-24-1, JAB-24-8, JAB24-10, JAB-24-14 e JAB-24-16.

Para frutos de qualidade, deseja-se menores valores de diâmetro longitudinal e transversal do lóculo, pois indicam as dimensões da cavidade interna dos frutos. Frutos com menor cavidade interna apresentam maior resistência ao transporte e vida útil pós-colheita prolongada (Costa e Pinto, 1977). As linhagens JAB-24-7, JAB-24-8 e JAB-24-19 apresentaram as menores cavidades internas, aliadas a boa espessura do mesocarpo.

Observou-se que a linhagem JAB24-11 apresentou o maior índice de formato (IF) diferindo apenas das linhagens JAB-24-6 e JAB-24-7. De acordo com Lopes (1982), os frutos das linhagens JAB-24-8, JAB-24-9, JAB-24-13, JAB24-15, JAB-24-17 e JAB-24-19 são classificados como esféricos $(\mathrm{IF}=1)$. As linhagens JAB-24-2, JAB-24-11, JAB24-14 e JAB-24-16 apresentaram frutos oblongos, com IF variando entre 1,12 e 1,15 . Os frutos das demais linhagens apresentaram IF variando entre 0,92 e 1,07 , valores bastante próximos de 1,0 , indicando formato próximo ao esférico (Tabela 1). Existem mercados para todos os formatos de fruto (Pádua, 2001), mas o formato esférico é o que mais fa-

Tabela 2. Valores médios de cinco características de frutos de 20 linhagens de melão rendilhado. Jaboticabal (SP), FCAV-UNESP, 2002.

\begin{tabular}{llcccc}
\hline \multirow{2}{*}{ Linhagens } & \multirow{2}{*}{ EMM (cm) } & \multirow{2}{*}{ EME (mm) } & TSS ('Brix) & \multicolumn{2}{c}{ Coloração } \\
\cline { 5 - 6 } & & & & Mesocarpo & Epicarpo \\
\hline JAB-24-1 & $2,3 \mathrm{bcd}{ }^{\circ}$ & $0,9 \mathrm{a}$ & $9,5 \mathrm{abc}$ & laranja & amarela \\
JAB-24-2 & $2,1 \mathrm{~cd}$ & $0,8 \mathrm{a}$ & $8,9 \mathrm{abc}$ & laranja & amarela \\
JAB-24-3 & $2,7 \mathrm{ab}$ & $0,9 \mathrm{a}$ & $9,2 \mathrm{abc}$ & laranja & amarela \\
JAB-24-4 & $2,6 \mathrm{abc}$ & $0,8 \mathrm{a}$ & $7,8 \mathrm{c}$ & laranja & amarela \\
JAB-24-5 & $2,2 \mathrm{bcd}$ & $0,8 \mathrm{a}$ & $9,1 \mathrm{abc}$ & laranja & amarela \\
JAB-24-6 & $2,3 \mathrm{bcd}$ & $0,9 \mathrm{a}$ & $9,2 \mathrm{abc}$ & amarela & amarela \\
JAB-24-7 & $2,3 \mathrm{bcd}$ & $0,9 \mathrm{a}$ & $11,2 \mathrm{a}$ & laranja & amarela \\
JAB-24-8 & $2,7 \mathrm{abc}$ & $0,7 \mathrm{a}$ & $9,2 \mathrm{abc}$ & laranja & amarela \\
JAB-24-9 & $2,6 \mathrm{abc}$ & $0,8 \mathrm{a}$ & $8,0 \mathrm{c}$ & laranja & amarela \\
JAB-24-10 & $2,3 \mathrm{bcd}$ & $0,9 \mathrm{a}$ & $8,8 \mathrm{abc}$ & laranja & amarela \\
JAB-24-11 & $2,4 \mathrm{abcd}$ & $0,9 \mathrm{a}$ & $9,5 \mathrm{abc}$ & laranja & amarela \\
JAB-24-12 & $2,5 \mathrm{abcd}$ & $0,8 \mathrm{a}$ & $10,2 \mathrm{abc}$ & amarela & amarela \\
JAB-24-13 & $2,4 \mathrm{abcd}$ & $0,8 \mathrm{a}$ & $8,2 \mathrm{c}$ & laranja & amarela \\
JAB-24-14 & $2,6 \mathrm{abc}$ & $0,8 \mathrm{a}$ & $8,7 \mathrm{bc}$ & laranja & amarela \\
JAB-24-15 & $2,4 \mathrm{bcd}$ & $0,7 \mathrm{a}$ & $9,0 \mathrm{abc}$ & laranja & amarela \\
JAB-24-16 & $2,2 \mathrm{bcd}$ & $0,8 \mathrm{a}$ & $9,6 \mathrm{abc}$ & laranja & amarela \\
JAB-24-17 & $1,9 \mathrm{~d}$ & $0,9 \mathrm{a}$ & $9,6 \mathrm{abc}$ & amarela & amarela \\
JAB-24-18 & $2,5 \mathrm{abcd}$ & $0,8 \mathrm{a}$ & $8,2 \mathrm{c}$ & laranja & amarela \\
JAB-24-19 & $2,3 \mathrm{bcd}$ & $0,7 \mathrm{a}$ & $11,0 \mathrm{ab}$ & amarela & amarela \\
JAB-24-20 & $2,9 \mathrm{a}$ & $0,7 \mathrm{a}$ & $7,8 \mathrm{c}$ & laranja & verde \\
\hline C.V. (\%) & 9,22 & 18,20 & 10,50 & & - \\
\hline DMS (Tukey) & 0,5905 & 0,3991 & 2,5194 & - & - \\
\hline MEe & & & & \\
\hline
\end{tabular}

Médias seguidas de mesma letra na mesma coluna não diferem entre si pelo teste de Tukey a $5 \%$ de probabilidade; $*$ EMM=Espessura média do mesocarpo $(\mathrm{cm})$; EME=Espessura média do epicarpo $(\mathrm{mm}), \mathrm{TSS}=$ teor de sólidos solúveis totais

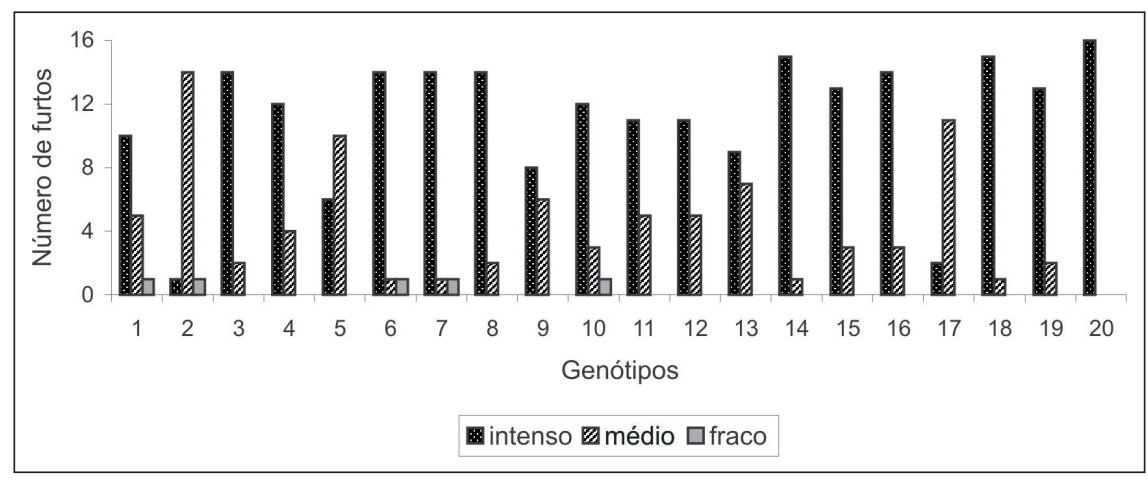

Figura 1. Intensidade de rendilhamento dos frutos comerciáveis de 20 linhagens de melão rendilhado. Jaboticabal (SP), FCAV-UNESP, 2002.

cilita o arranjo dos frutos nas embalagens utilizadas atualmente.

Não houve diferença entre as linhagens quanto à espessura do epicarpo do fruto. Já para a espessura média do mesocarpo, o maior valor foi observado na linhagem JAB-24-20 que não diferiu das linhagens JAB-24-3, JAB-248, JAB-24-4, JAB-24-9, JAB-24-14, JAB-24-12, JAB-24-18, JAB-24-11 e JAB-24-13, o que é desejável pois o mesocarpo é a parte do fruto consumida e portanto, mais valorizada (Tabela 2). Sendo assim, a linhagem JAB-24-20 é a mais indicada para a obtenção de frutos com bons valores de mesocarpo, semelhantes aos valores que têm sido obtidos por outros autores com híbridos comerciais (Rizzo e Braz, 2001).

Para o teor total de sólidos solúveis, o maior valor observado ocorreu em frutos da linhagem JAB-24-7, que atingiu 
$11,2^{\circ}$ Brix, valor muito próximo à faixa considerada excelente para qualidade de fruto (12 a 15\%) (Odet, 1992; McCreight et al., 1993; Gorgatti Neto et al., 1994; Silva et al., 2000). Contudo, a linhagem JAB-24-7 diferiu apenas das linhagens JAB-24-14, JAB-2413, JAB-24-18, JAB-24-9, JAB-24-4 e JAB-24-20, as quais apresentaram valores médios de 7,8 a 8,7 ${ }^{\circ} \mathrm{Brix}$, considerados pelos autores anteriormente citados, como não comerciais (menor que 9\%). Estes valores estão próximos aos encontrados por Hartz (1997), Rizzo e Braz (2001) e Gusmão (2001), em avaliações de híbridos comerciais, o que indica que as linhagens testadas têm bom potencial para a manutenção de altos teores de sólidos solúveis.

A cor laranja do mesocarpo foi predominante nas linhagens avaliadas, ocorrendo em $75 \%$ delas (Tabela 2). Segundo Duarte (2003), existe uma tendência de mercado pelo consumo de melões com mesocarpo laranja ou salmão, tendo estas linhagens potencial comercial.

Houve variação na intensidade de rendilhamento dos frutos produzidos, mas a maioria destes apresentaram rendilhamento intenso (Figura 1). Apenas as linhagens JAB-24-2, JAB-24-5 e JAB-24-17 apresentaram maior número de frutos com rendilhamento médio.

Comercialmente, deseja-se que os frutos de melão rendilhado tenham alta intensidade de rendilhamento, pois este aspecto é um dos atrativos para o consumo dos frutos deste tipo de melão (McCreight et al., 1993; Gorgatti Neto et al., 1994; Silva et al., 2000).

Considerando-se as características avaliadas e o mercado consumidor, as linhagens JAB-24-3, JAB-24-4, JAB24-5, JAB-24-7, JAB-24-8, JAB-24-9, JAB-24-11, JAB-24-12, JAB-24-13, JAB-24-14, JAB-24-15, JAB-24-18 e JAB-24-20 se destacaram das demais, na maioria das características, demonstrando bom potencial para obtenção de híbridos comerciais.

\section{LITERATURA CITADA}

COSTA, C.P.; PINTO, C.A.B.P. Melhoramento de hortaliças. Piracicaba: ESALQ, Depto. de Genética, 1977. 319 p.

DUARTE, R.L.R.; ANDRADE JUNIOR, A.S. Estudo da oferta e comercialização de melão na CEASA-PI (1991-1996). Horticultura Brasileira, Brasília, v.21, n.1, p.127-131, 2003.

GORGATTI NETO, A.; GAYET, J.P.; BLEINROTH, E.W.; MATALLO, M.; GARCIA, E.E.C.; GARCIA, A.E.;ARDITO, E.F.G.; BORDIN, M.R. Melão para exportação: procedimentos de colheita e pós-colheita. Brasília: EMBRAPA-SPI, 1994. p.37.

GUSMÃO, S.A.L. Interação genótipo x ambiente em híbridos de melão rendilhado (Cucumis melo var. reticulatus Naud.). 2001. 143 f. (Tese doutorado) FCAV, UNESP, Jaboticabal, 2001.

HARTZ, T.K. Effects of drip irrigation scheduling on muskmelon yield and quality. Scientia Horticulturae, v.69, p.117-122, 1997.

LESTER, G.E. Melon (Cucumis melo L.) fruit nutritional quality and health funcionality. HortTechnology, v.7, n.3, p.222-227, 1997.
LESTER, G.E.; TURLEY, R.M. Chemical, physical and sensory comparisons of netted muskmelon fruit cultivars and breeding lines at harvest. Journal Rio Grande Valley Horticultural Society, v.43, p.71-77, 1990.

LOPES, J.F. Melhoramento genético (chuchu, melancia, melão e pepino). Informe Agropecuário, Belo Horizonte, v.8, n.85, p.61-65, 1982.

McCREIGHT, J.D.; NERSON, H.; GRUMET, R. Melon. In KALLOO, G.; BERGH, B.O. Genetic improvment of vegetable crops. p.267-294, 1993. ODET, J. Le melon. Paris: CTIFL, 1992. 295 p. PÁDUA, J.G. Cultivo protegido de melão rendilhado em duas épocas de plantio. 2001. 108 f. (Tese doutorado) FCAV, UNESP, Jaboticabal, 2001.

RAIJ, B.; CANTARELLA, J.A.; QUAGGIO, R.; FURLANI, A.M.C., ed. Recomendações de adubação e calagem para o Estado de São Paulo. 2. ed. Campinas: Instituto Agronômico \& Fundação IAC, 1996. p.285.

RIZZO, A.A.N.; BRAZ, L.T. Características de cultivares de melão rendilhado cultivadas em casa de vegetação. Horticultura Brasileira, Brasília, v.19, n.3, p.370-373, 2001

RIZZO, A.A.N. Obtenção e avaliação de genótipos de melão rendilhado em ambiente protegido. 2004. 38 f. (Tese doutorado) FCAV, UNESP, Jaboticabal, 2004

ROBINSON, R.W., DECKER-WALTERS, D.S. Cucurbits. CAB Inernational, Cambridge, 1997, 226 p.

SILVA, H.R.; SILVA, H.R.; MAROUELLI, W.A.; SILVA, W.L.C.; SILVA, R.A.; LEOPOLDO, A.O. RODRIGUES A.G.; SOUZA, A.F.; MAENO, P. Cultivo do meloeiro para o Norte de Minas Gerais, Brasília: EMBRAPA, 2000. 24 p. (Circular Técnica, 20).

SIVIERO, P. La cultivazione del melone. Verona: Edizioni L'Informatore Agrario, 1993. p.208.

WELLES, G.W.H.; BUITELAAR, K. Factors affecting soluble solid content of muskmelon (Cucumis melo L.). Netherland Journal of Agriculture Science, v.36, p.239-246, 1988. 